\title{
TIPPER FOR CONTROLLING FLOW BOXES OF POTATOES IN GRADING STATIONS
}

\author{
R. G. SALIM*
}

\section{ABSTRACT}

The main objectives of this study were to manufacture of tipper for controlling flow boxes of potatoes in grading stations of investment companies as alternate to the costly (tenfold) of importing box tipper using the Egyptian facilities such as row material, local workshops and labors required with (one) tenth cost. While manufacturing of tipper take considered heavy duty different emptying angles of box tipper, 2,000kg lift as maximum lifting weight, single machine with twin hydraulic rams, Manual override in control panel, one set cradle inserts, adjustable height legs to give maximum height under conveyor of $1.6 \mathrm{~m}$, side safety guards, Light guards (not fitted when machine rose by $1.8 \mathrm{~m}$ ), Minimum cycle time 28 seconds and Manually adjustable flow door. Measuring indicators were tested for the local manufactured tipper at the tested emptying angles (degrees), hydraulic pressure (bar) and box capacity (ton). It was found that using the tested local tipper with emptying angle $160^{\circ}$ and 100 bar hydraulic pressure under 1.25 ton box capacity gave the best results in all treatment and achieving the minimum cycle time 28 seconds to empty the box and minimum bruises Therefore it is advisable to use the local manufacture tipper that showed the best results comparing the imported tipper that costing the tenfold compared to the local tipper and gave the same target.

\section{INTRODUCTION}

7 he investment companies decided to plant the wide area of potatoes in land new reclaimed under center pivot irrigation Lystem to grade the harvested potatoes after finishing the harvesting season pulled the closely packed boxes of potatoes ( 1 to 1.5 tons) up to four boxes vertically from refrigerator to start grading, the local manufactured tipper to empty the boxes in the hopper of grading station.

\footnotetext{
*Agric. Eng. Res. Inst. Agric. Res. Center
} 
Michael Thornton and William Bohl (1995) reported that potato bruising is a serious problem in the potato industry. The effects of bruising are felt by every handler and consumer of potatoes and are a major economic drain on the industry. Potato bruising is estimated to cost the U.S. potato industry at least \$298 million annually. Most of the cost of bruising is eventually passed back to the grower in the form of lower prices, reduced demand, and increased storage losses. Bruising costs the potato industry because it: - increases storage losses due to shrinkage and disease - increases labor costs for trimming and inspecting increases the cost of the raw product through greater trim losses $\bullet$ lowers the quality of the final product - increases the incidence of disease and decreases shelf life - reduces the appeal of fresh potatoes to wholesale and retail customers With bruise-free incentive clauses in processor contracts and an increasing emphasis on limiting external grade defects. Also, they added that, there are four major types of potato bruise damage: skinning, black spot bruise, shatter bruise, and pressure bruise. The first three result from the potato hitting objects, such as equipment, clods, rocks or other tubers during harvesting and handling operations. Rousselle et al., (1996) showed that bruises, defined as colored marks that remain after two consecutive passes with a kitchen vegetable peeler. Lifting and stock age of tubers are responsible for up to 40-50 percent of bruises on domestic potatoes, and up to 100 percent on loose industrial potatoes. Bruised potatoes lose weight due to an increase in transpiration, they lose starch because of increased respiration, and they are more prone to pathogen invasion. Noordam et al., (2000) mentioned that grading is particularly important for potatoes because the size, shape, color, and defects depend greatly on environmental conditions and handling, and is performed primarily by trained human inspectors who assess the potatoes by "seeing" or "feeling" a particular quality attribute. However, there are some disadvantages to using human inspectors, including inconsistency, short supply of labor, and the expense of the large amounts of time required due to the huge volume of production. Product experts characterize potato defects and diseases based on color and shape features, and thus computer vision may improve inspection results and be able to take over the visually intensive inspection work from human 
inspectors. Automation is desirable because it can ensure consistency in product quality and can handle large volumes. A completely automated inspection station requires the incorporation of machine vision and automation into a system consisting of the appropriate hardware and software for both product handling and grading. Factors such as size, shape, greening, cracks, scab, etc. determine the final grade of a potato. Marique et al., (2003) indicated that every batch of potato tubers must be tested for quality before sale, and visual inspection is of great importance. This is true not only for stocks intended for industrial use, but also and especially for those intended for domestic use, since potential consumers attach predominant importance to external appearance. There exists a real need for standardization of analysis, since quality evaluation determines the acceptance or rejection of submitted potato batches and, of course, the subsequent payment of producers. Marique et al, ( 2005) stated that evaluation of surface defect depends on the particular potato variety tested, as flesh color ranges from creamy white to buttery yellow. Moreover, defects can show broad variations of shape, aspect, and color (white, gray, bluish, brown, black, etc.). In practice, several very different criteria are evaluated, either after harvest or upon delivery. The main objective of the present investigation is to choose a suitable mechanism for emptying of potatoes boxes. To study the possibility of utilizing it under the Egyptian new reclaimed land and to suit large holding farms of investment companies using available facilities on farms. Field experiments were carried out to evaluate the performance of local fabricated box tipper at different hydraulic pressure, angles of emptying and capacity of boxes. Time of emptying, bruised potatoes, power required and cost of emptying operation were therefore studied.

\section{MATERIALS AND METHODS}

The tested box tipper was constructed and fabricated at the workshop of Tanta Motors Company Gharbia Governorate. During the construction of the tipper the following points have been taken into consideration:

1- All parts are made of local materials, as show in below.

2- The manufactured tipper should have simple mechanisms and shape. 
3- Using the fabricated tipper caused minimum bruises of potatoes tubers and lowest time empty of boxes.

4- The manufactured tipper suitable for working in international grading stations models with the same efficiency of imported tipper.

5- Minimum cost to an increase in profit.

The price of fabricated tipper 30000 E.P and manufactured to suitable empty of boxes under Egyptian conditions and it consists of chassis made of square beam $10 \mathrm{~cm}$, the sides made of square beam $6 \mathrm{~cm}$ and sheet $8 \mathrm{~mm}$. There is an extension part to easy load of the tipper by the fork lift. The box of tipper made of sheet $5 \mathrm{~mm}$ thickness, supported with square beam $8 \mathrm{~cm}$ and $5 \mathrm{~mm}$ thickness. The hitching point made of $10 \mathrm{~mm}$ thickness sheet. The lower third folder of sheet thickness $2 \mathrm{~mm}$ and the rest side folder hooking wire thickness of $3 \mathrm{~mm}$. the external sides easy to remove and install. The box of tipper increased front link to collect the potatoes at discharge. The height of the tipper controlled through perforated square beams gradually. The tipper works on bearing by closing hydraulic circle and the external sides made of standard iron angle $4 \mathrm{~cm}, 2 \mathrm{~m}$ length and height of $1.8 \mathrm{~m}$. The dimensions of tipper box were $2 \mathrm{~m}$ length and width of $1.2 \mathrm{~m}$ and the load of tipper from 0.75 to 1.5 ton. The hydraulic circle consists of two hydraulic pistons, electrical motor $3 \mathrm{Hp}$ with pump, regulator of pressure, oil filters and hydraulic hoses $3 / 8$ inch. The capacity of oil tank was 35 liter and all of the welding $\mathrm{Co}_{2}$. The main component of the local box tipper and its dimensions demonstrated in figs. (1 and 2) and figs. (3A, B and C). A field experiments were carried out in new reclaimed land under center pivot irrigation system in Lehaa for trade and agricultural investment company in Garf Hussien, Aswan Governorate to empty the tuber of potatoes in a large holding area (pivots) and evaluate machine performance during the emptying of potatoes boxes operation by local tipper for the first time in Egypt. The experimental crop of the present study was potatoes (sponta). The chosen variety was planted in an area of about 400 feddan Measuring indicators were tested for the emptying angles (degrees), hydraulic pressure (bar) and box capacity (kg). 


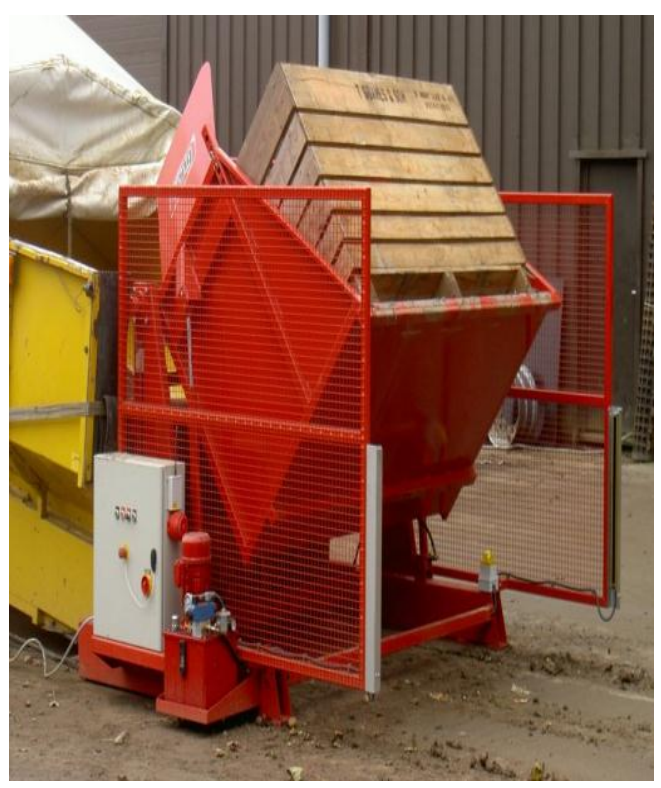

Figure (1): The local boxes tipper.

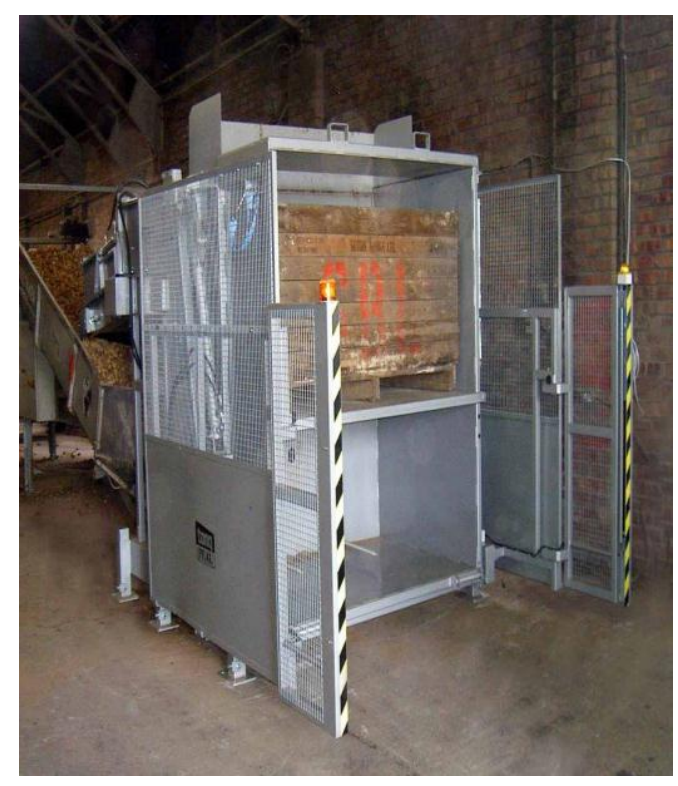

Figure (2): The import boxes tipper.

\section{Theoretical considerations:}

To calculate the flow rate (volumetric) and the required horsepower for the local tipper at different hydraulic pressure can use the following equation:

- $\quad$ Flow rate:

$$
\mathrm{Q}=\mathrm{A} \times \mathrm{V}
$$

Where:

$\mathrm{Q}=$ flow rate of the hydraulic oil $\left(\mathrm{Cm}^{3} / \mathrm{sec}\right.$. $)$.

$\mathrm{V}=$ velocity of flow $(\mathrm{Cm} / \mathrm{sec}$. $)$ and $\mathrm{A}=$ the area of piston $\left(\mathrm{cm}^{2}\right)$

From above equation:

$\mathrm{A}=\pi / 4 \times \mathrm{D}^{2}, \quad \mathrm{~A}=0.785 \times 10.55 \times 10.55=86.54 \mathrm{~cm}^{2}$

$\mathrm{V}=3.08 \mathrm{Cm} / \mathrm{sec}$. measured by flow meter device.

$\mathrm{Q}=3.08 \times 86.54=266.66 \mathrm{Cm}^{3} / \mathrm{sec} .=16 \mathrm{~L} / \mathrm{min}$.

\section{- Power required $(\mathrm{kW})$}

- Electrical required power:

Electrical Power required for three phase voltage (380 Volts) and current (4.9 Amps) was experimental determined by using an equation of the power as follows:

$P_{0}=$ I.U. $3^{1 / 2} \cdot \cos \varnothing / 1000$ 

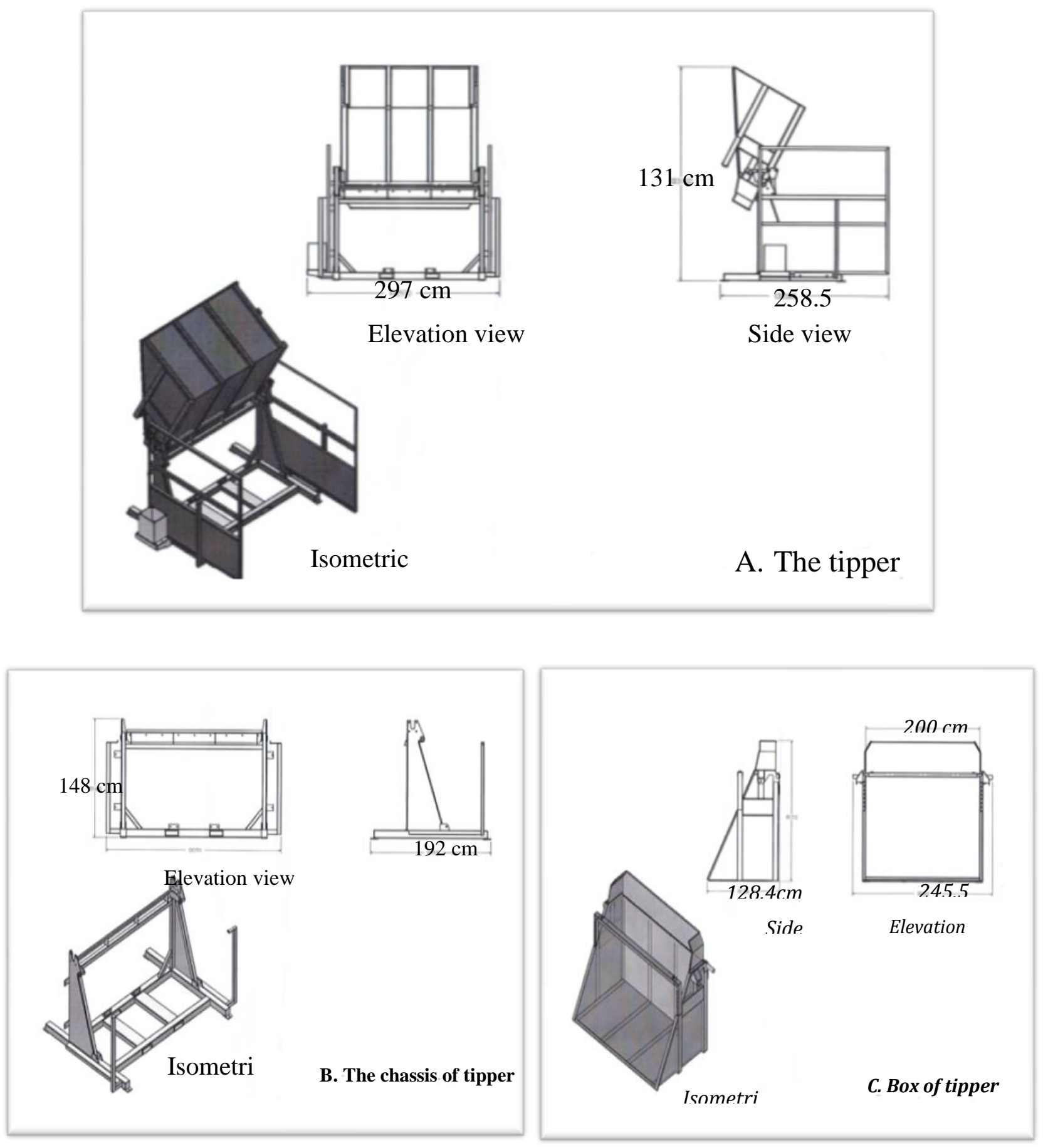

Figure (3 A, B and C): The different views for the box tipper components 
Where:

$\mathrm{P}_{\mathrm{o}}=$ Real power, $\mathrm{Kw}, \mathrm{I}=$ current $(\mathrm{A}$, amps), $\mathrm{U}=$ voltage $(\mathrm{V}$, volts $)$ and $\mathrm{P}_{\mathrm{f}}=\cos \varnothing=$ Power factor $(0.70-0.95)$

$$
\mathrm{P}_{\mathrm{o}}=4.6 \times 380 \times 3^{1 / 2} \times 0.75=2.25 \mathrm{~kW}
$$

\section{- Mechanical required power:}

$\mathrm{Hp}=\mathrm{Q} \times \mathrm{P}$

Where:

$\mathrm{Hp}=$ power $(\mathrm{kW}), \mathrm{Q}=$ flow rate (liter/minute) and $\mathrm{P}=$ pressure $(\mathrm{bar})$

At $\mathrm{Q}=18 \mathrm{~L} / \mathrm{min}$. and pressure $=100 \mathrm{bar}$

$\mathrm{P}(\mathrm{kW})=(16 \times 1000 / 60) \times 100 \times 1.019716213 \times 0.0001=3.02 \times 0.85=$

$2.24 \mathrm{~kW} \times 1.34=3.0 \mathrm{Hp}$

Table (1) the required horsepower of local tipper at flow rate $16 \mathrm{l} / \mathrm{min}$., diameter of pistons $10.5 \mathrm{~cm}$ and voltage 380 three phase, current 4.9 ampere at different hydraulic pressure.

\begin{tabular}{|c|c|c|c|}
\hline Pressure (bar) & 90 & 100 & 110 \\
\hline Required horsepower (Hp) & 2.45 & 2.73 & 3 \\
\hline
\end{tabular}

From the above calculations one can noticed that, the manufactured tipper need pistons with diameters $10.55 \mathrm{~cm}$, hydraulic pump give 16 liter/minute flow rate and power of electric motor $3.0 \mathrm{hp}$ to can dealing easily at emptying of potatoes boxes.

$$
\zeta=\frac{E p}{M p} x 100
$$

From the above equation noticed that the efficiency of converting $(\zeta$ ) of electrical power $\left(\mathrm{E}_{\mathrm{p}}\right)$ to mechanical power $\left(\mathrm{M}_{\mathrm{p}}\right)$ more than $80 \%$ as follows:

$$
\zeta=\frac{1.84}{2.25} \times 100=82 \%
$$

\section{Test factors}

The following parameters were studied to evaluate the performance of the tipper with three replicates for each parameter.

- Four emptying angles $\left(140,150,160\right.$ and 170 degree) named $A_{1}, A_{2}, A_{3}$ and $\mathrm{A}_{4}$ : emptying angle is calculated by measuring the angle of box from horizontal at maximum of box emptying angle level to cover 
specified experiment and the successes of emptying operation without bruising for potatoes tubers.

-Three levels of hydraulic oil pressures $\left(90,100\right.$ and 110 bar) Named $B_{1}$, $\mathrm{B}_{2}$ and $\mathrm{B}_{3}$.

-Three levels of box capacity $\left(0.750,1.000\right.$ and 1.25 ton) Named $\mathrm{Bc}_{1}$, $\mathrm{Bc}_{2}$ and $\mathrm{Bc}_{3}$.

These measuring indicators were tested for the four emptying angles, three oil pressures and three levels of box capacity for sponta potatoes variety. The box width was adjusted at $1.2 \mathrm{~m}$, the height was adjusted at $1.8 \mathrm{~m}$ and the length adjusted at $2 \mathrm{~m}$ for emptying of potatoes tubers.

\section{Measurements:}

\section{1- Bruising of tubers (\%)}

The emptying operation performance was evaluated by observing the potatoes tipper through, correct empty tubers. During the experimental work, the performance of tipper assessed by taking randomly selected 100 tubers of potatoes before and after emptying operation. So bruising can be estimated easily before that caused while harvesting and packing in boxes and after that caused while emptying. The percentage of the bruising of tubers, which are used to control tipper performance, can be calculated as the following:

Bruised tubers $\%=\frac{\text { No. of bruised } \cdot \text { tubers }}{\text { Total No. of } \cdot \text { tubers } \cdot \text { in } \cdot \text { sample }} x 100$-general mean of previous bruised tubers

\section{2- Time of emptying (sec.)}

\section{The time of emptying (Te.) was calculated by the following equation:}

$$
T e=T t+T p
$$

Where:

Te: time of emptying (sec.), Tt: time of emptying of the box and

Tp: time consumed in putting or pulling the box on/from the tipper

\section{The statistical analysis:}

The experiments were arranged in split plot design with three replicates by using Minitab software (Regression analysis and ANOVA). The analysis of variance was done to investigate the significance of the 
studied variables. Also, the best fit multiple linear regression equations and Regression Coefficient, $\mathrm{R}^{2}$ were developed for each variable.

\section{RESULTS AND DISCUSSION}

Bruised potatoes for tested tipper at the hydraulic pressure $\left(B_{1}, B_{2}\right.$

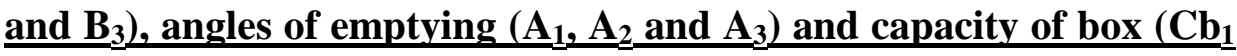
$\mathrm{Cb2}$ and $\mathrm{Cb}_{3}$ ) for potatoes (sponta).

The bruised potatoes percentage for the tipper at the tested hydraulic pressure (bar), angles of emptying and capacity of box for potatoes (Sponta) is presented in Figure (4). The achieved results revealed that both factors of hydraulic pressure and angles of emptying affected deeply the bruised potatoes percentage at constant capacity of box for potatoes. The results showed that increasing hydraulic pressure, angles of emptying and capacity of box resulted in increasing bruised potatoes percentage. The overall data showed that, with the hydraulic pressure 100 bar and capacity of box 1.25 ton under angles of emptying of 140, 150, 160 and 170 degree, average of bruised potatoes percentage was 2.6, 4.1, 5.2 and $6.1 \%$ respectively. From the figures, it was clear that the bruised potatoes percentage was higher at $\mathrm{B}_{3}$ than $\mathrm{B}_{1}$ and $\mathrm{B}_{2}$ hydraulic pressure. The highest value of bruised potatoes percentage $6.9 \%$ was obtained under hydraulic pressure of 110 bar $170^{\circ}$ angle of emptying and 1.25 ton capacity of box while the lowest value of bruised potatoes percentage was $1.2 \%$ under hydraulic pressure 90 bar, $140{ }^{\circ}$ angle of emptying and 0.75 ton capacity of box. Generally, one can noticed that, there are a direct proportional between bruised potatoes and the three tested factors; this may be due to cumulative the potatoes tuber at increasing weight of box, forced drop of tubers at increasing the pressure and emptying angles. Also, from the mentioned figures, one can noticed that the curve of imported tipper closer to the results of local tipper at 100 bar with the other parameters. Data analyzed showed that there was a significant effect for using the high pressure, capacity of box and angle emptying (p $<0.01)$ under the same conditions of tested factors.

A multiple regression analysis carried out taking time of emptying, as dependent variable and hyd. pressure, angle of emptying and capacity of box as independent variables. 

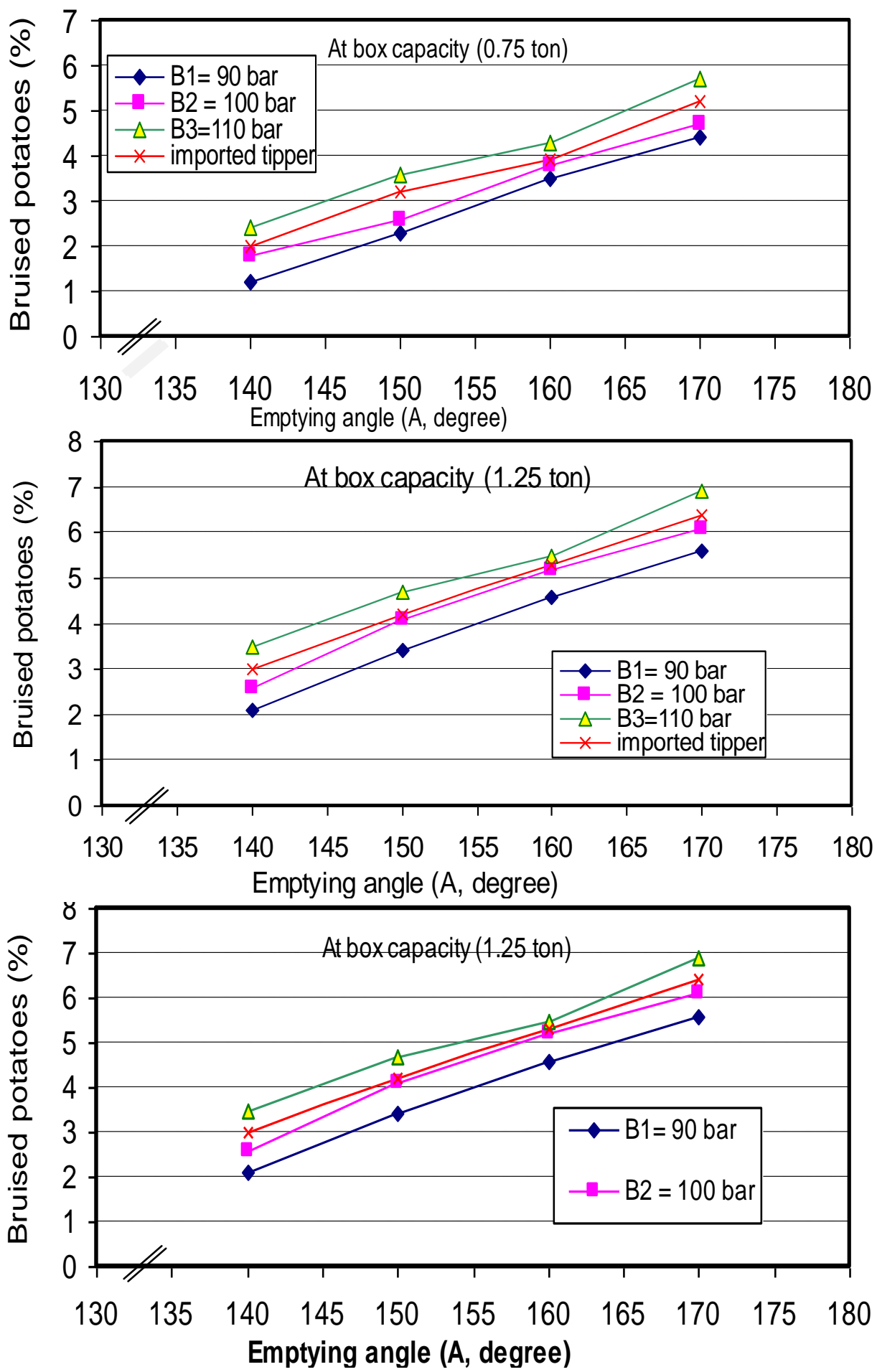

Figure 4: The bruised potatoes (\%) for the tipper at the tested hydraulic pressure (bar), emptying angles (degree) and capacity of box (ton) for potatoes (Sponta). 
Bp $(\%)=-13.5-0.375$ hyd. Pres. (bar) -0.326 angle of emptying $\left({ }^{0}\right)+$ 4.45 capacity (ton)
$\mathrm{S}=0.530798$
$\mathrm{R}-\mathrm{Sq}=87.2 \%$
$\mathrm{R}-\mathrm{Sq}(\operatorname{adj})=86.0 \%$

Analysis of Variance

$\begin{array}{lccccc}\text { Source } & \text { DF } & \text { SS } & \text { MS } & \text { F } & \text { P } \\ \text { Regression } & 3 & 61.567 & 20.522 & 72.84 & 0.000 \\ \text { Residual Error } & 32 & 9.016 & 0.282 & & \\ \text { Total } & 35 & 70.583 & & & \end{array}$

Data were graphically in fig. (5), generally, showed that the time of emptying decreased with increasing hydraulic pressure (B), angles of emptying (A) and capacity of box $\left(\mathrm{C}_{\mathrm{b}}\right)$. At the same time, drawn data in mentioned figures caused flow curves. This meant that there was a direct relationship between time of emptying and three tested factors. On the other hand, emptying time of 24 second achieved at 170 degree (emptying angle) considered superior productivity (time of emptying) over the three others $\left(140,150\right.$ and $\left.160^{\circ}\right)$. Also, mentioned data showed the existence of a significant influence on time of emptying consumed at all treatments under study. In other words, the interaction among all the same mentioned treatments under study caused a significant impression on time of emptying. The largest consumed time of emptying was 50 second achieved at a hydraulic pressure of 90 bar, box capacity of 1.25 ton and angle of emptying $140^{\circ}$. The smallest consumed time of emptying was 24 second obtained at a hydraulic pressure of $110 \mathrm{bar}$, box capacity of 0.75 ton and angle of emptying $170^{\circ}$.. One could say that the emptying time decreased with increasing the three tested factors and vice versa. This could be as a result of slowing fall potatoes and accumulated of tubers causing decreasing velocity of potatoes tubers emptying. This may be led to increasing time of emptying and decreasing the number of emptying boxes in unit of time. Also, from the mentioned figures, one can noticed that the curve of imported tipper closer to the results of local tipper at 100 bar with the other parameters.

A multiple regression analysis was carried out taking time of emptying, as dependent variable and hydraulic pressure, angle of emptying and capacity of box as independent variables. 
FARM MACHINERY AND POWER
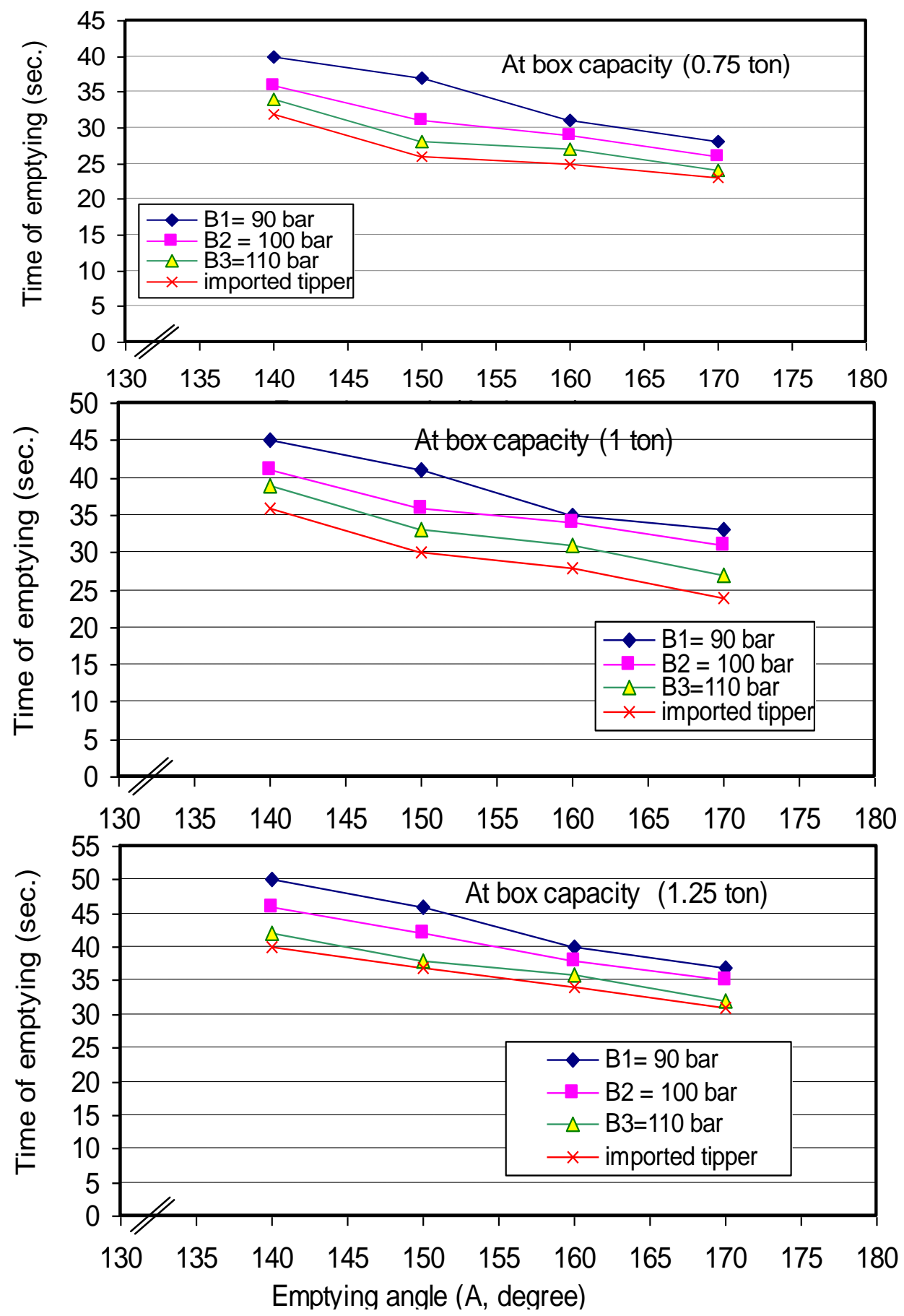

Figure 5: The time of emptying (sec.) for the tipper at the tested hydraulic pressure (bar), emptying angles (degree) and capacity of box (ton) for potatoes (Sponta). 
T e. $($ sec. $)=104+1.21$ hyd. Pre. (B) -1.12 angle of emptying $(A)-15.1$ capacity of box $\left(\mathrm{C}_{\mathrm{b}}\right)$

$\mathrm{R}-\mathrm{Sq}=93.6 \%$

The regression equation is

$\mathrm{Te}(\mathrm{sec})=.104+1.21$ hyd. Pres. (bar)-1.12 angle of emp. $\left({ }^{0}\right)-15.1$ capacity (ton)

$S=4.13769$

$\mathrm{R}-\mathrm{Sq}=90.4 \%$

$\mathrm{R}-\mathrm{Sq}(\operatorname{adj})=86.7 \%$

Analysis of Variance

Source

DF

SS

MS

$\mathrm{F}$

$\mathrm{P}$

Regression

3

835.12

278.37

16.26

0.000

Residual Error 32

547.86

17.12

Total 35

1382.97

Data in Fig. (6) show the intersection between two curves that represent the emptying time consumed and bruised potatoes ratio at the angles of emptying $\left(160^{\circ}\right)$, with fixed hydraulic pressure at (100 bar) and capacity of box (1.25 ton). At the same time, drawn data in mentioned figures caused flow curves (descending) with time of emptying consumed while caused ascending curve with bruised potatoes ratio, this meant that there was an indirect relationship between time of emptying and three tested factors and a direct proportional between bruised potatoes ratio and three tested factors. This indicates that optimum angle of emptying was the $\left(160^{\circ}\right)$.The high angle of emptying; pressure of hydraulic oil and capacity of box may be attributed to the excessive load of the tubers material on the grading sieves. Excessive load occurred by increasing angle of emptying which cause rapid motion of the tubers material. Due rapid motion led to some tubers which did not have the chance to go regular speed as the graded material layers of the grading sieves. Also, from the mentioned figures, one can noticed that the curve of imported tipper closer to the results of local tipper at 110 bar with the other parameters. 


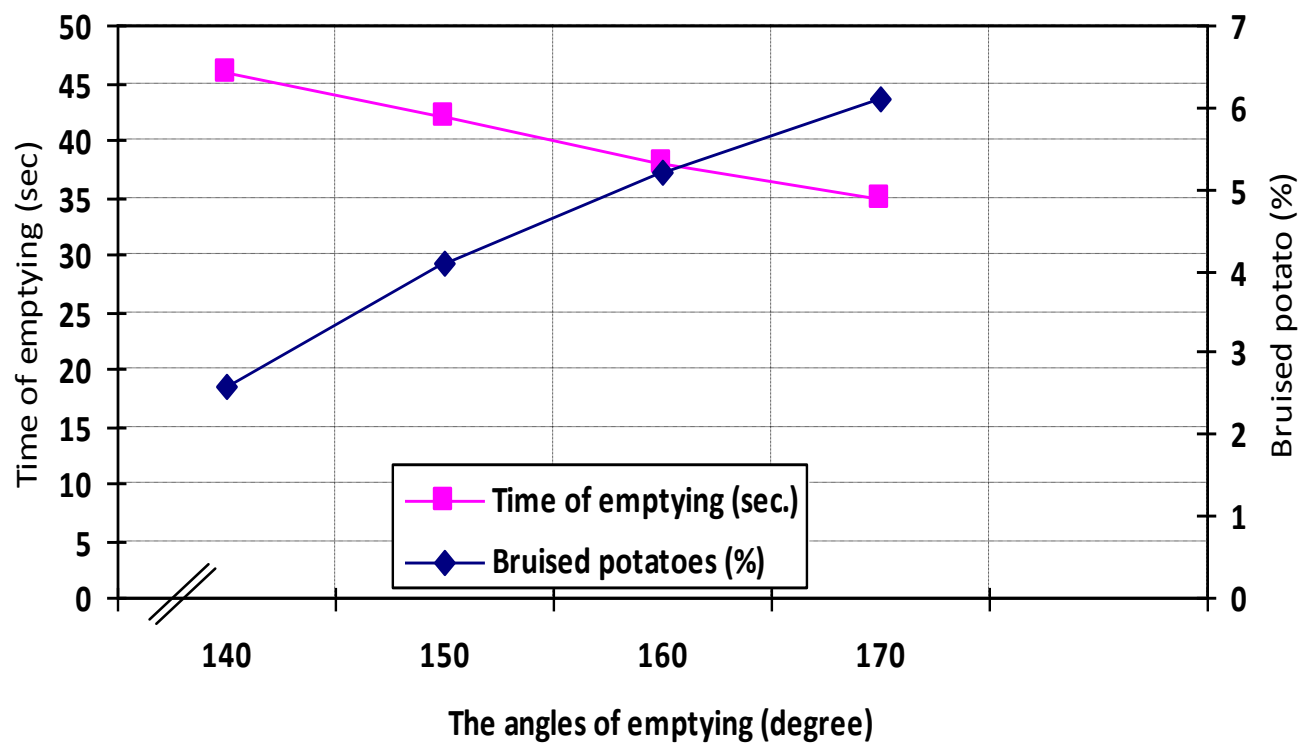

Figure 6: The optimum factors that obtaining the minimum bruised potatoes at least time of emptying possible achieved at intersection point

The required power (Hp) and cost of the manufactured tipper for emptying the boxes of potatoes (Sponta).

From the foregoing mentioned theoretical calculation that limited the required horsepower and others specification of hydraulic circle. At the same time, can calculated the cost of tipper at $2.24 \mathrm{~kW}$ electrical consumed 1.34 L.E per hour, labor cost 10 L.E per hour, 4 L.E oil hydraulic per hour, from table (1) one can said that the cost of import tipper increased $5.85 \%$ more than the local tipper.

\subsection{Cost evaluation:}

Fixed cost calculated as following:

Deprecation for local tipper $=\frac{P-S}{L}=\frac{30000-3000}{10}=2700$ L.E

Deprecation for export tipper $=\frac{P-S}{L}=\frac{300000-3000}{10}=27000 \mathrm{L.E}$

Where:

$\mathrm{p}=$ price of the new tipper, $\mathrm{S}=$ price of scrap tipper $(10 \%)$ and $\mathrm{L}=$ age of tipper 
Table (2) Comparison between cost of local and export tipper for one emptying ton .

\begin{tabular}{|c|c|c|}
\hline import tipper & Local tipper & Items \\
\hline EGYP /ton & EGYP/ton & Fixed Costs: \\
\hline 0.495 & 0.0450 & Deprecation \\
6.880 & 0.0600 & Interest (12.5\%) yearly \\
0.081 & 0.0067 & Taxes, Insurance and shelter (1.5\%) purchasing price \\
\hline 7.456 & 0.1117 & Total Fixed costs \\
\hline EGYP/h & EGYP/h & Operating costs: \\
\hline 0.126 & 0.2600 & power \\
0.125 & 0.1250 & Repair and maintenance costs \\
0.100 & 0.2000 & labor \\
0.026 & 0.0026 & Oil and filters cost \\
\hline 0.377 & 0.5876 & Sub-total operating costs \\
\hline 7.833 & 0.6993 & Sub-total costs \\
\hline \multicolumn{2}{|c|}{11.2 fold } & Cost of ton of imported tipper 11.2 fold of local tipper \\
\hline
\end{tabular}

\section{REFERENCES}

MariqueT, KharoubiA, Bauffe P, DucattillonC(2003) Modelling of fried potato chips color classification using artificial neural network. Journal of Food Science, 68, 2263-2266.

Marique T, Pennincx S, Kharoubi A (2005) Image segmentation and bruise identification on potatoes using a Kohonen's self-organizing map. J. of Food Science, 70, 415-417.

Michael Thornton \& William Bohl (1995) Preventing Potato Bruise Damage. College of agriculture, university of Idaho Cooperative Extension System Agricultural Experiment Station BUL 725 (Revised)

Noordam JC, OttenGW,TimmermansAJM, vanZwolBH(2000) High speed potato grading and quality inspection based on a color vision system. Proceedings of SPIE: The International Society for Optical Engineering, 3966, 206-219.

Rousselle P, Robert Y, Crosnier JC (1996) La pomme de terre. Production, amélioration, ennemis et maladies, utilisations. Paris: INRA éditions, p. 607. 


\section{الملخص العربي \\ الة لتفريغ صناديق البطاطس فى محطات الفرز

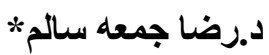

أجريت هذه التجربة على انتاجية مساحة . . ـ فدان بطاطس فى شركة لحاء للتجارة و الإستثمار

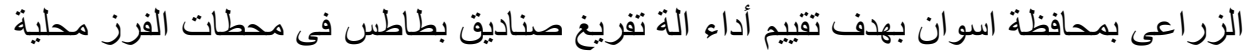

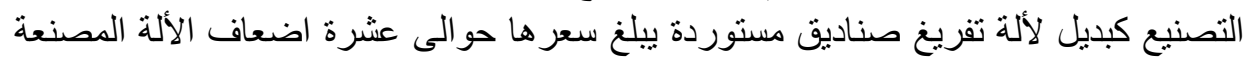

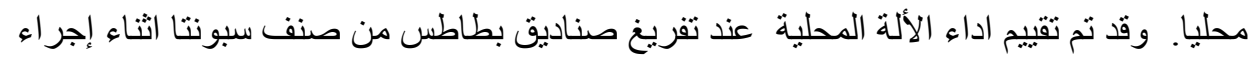

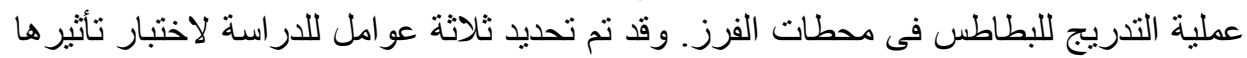

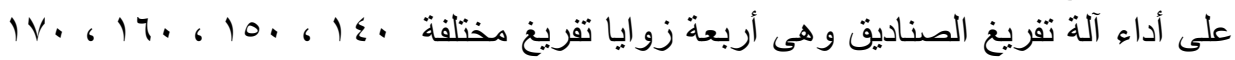

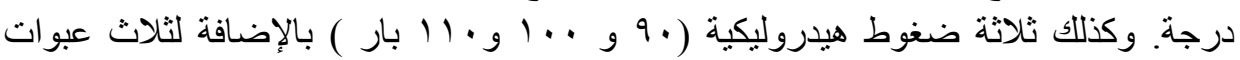

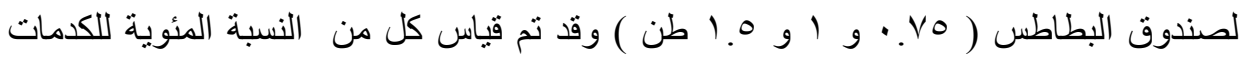

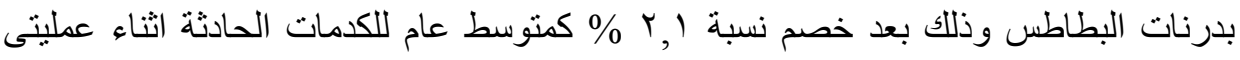

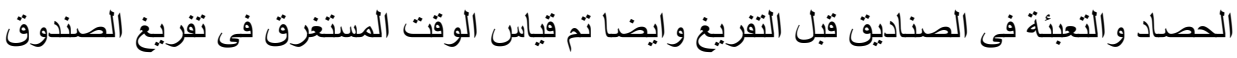

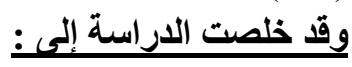

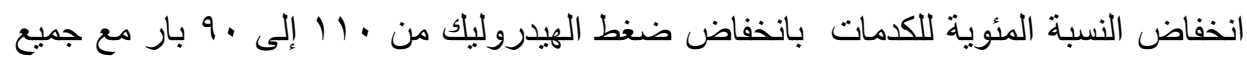

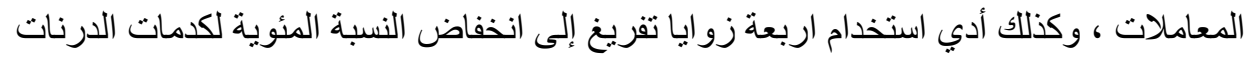

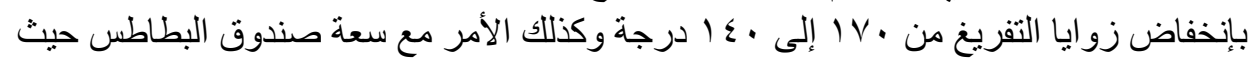

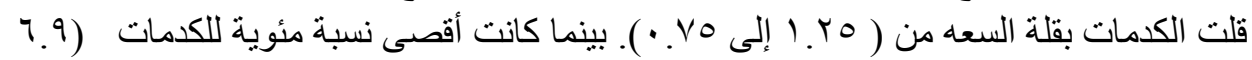

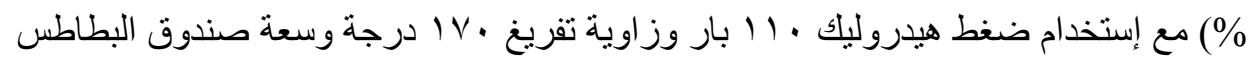

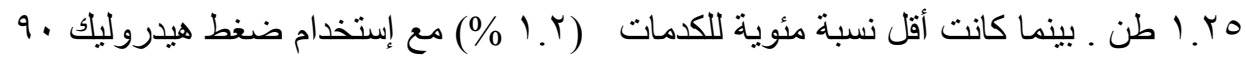

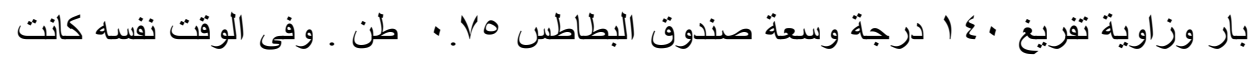

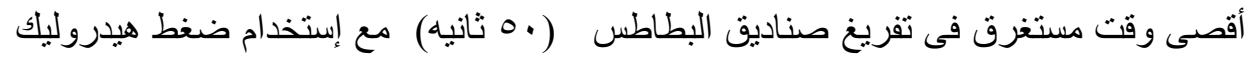

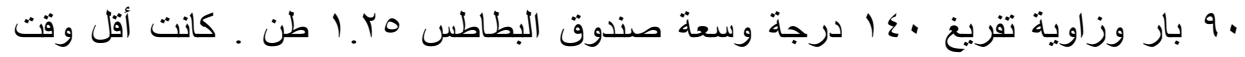

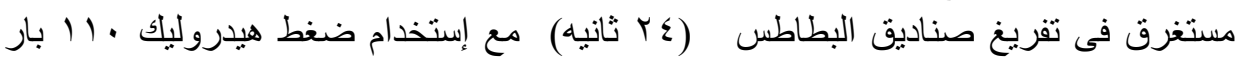

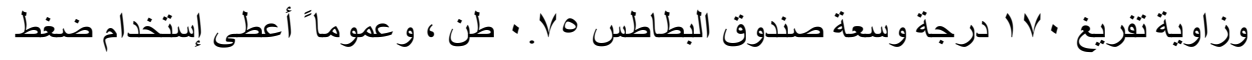

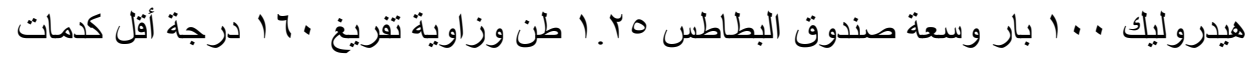

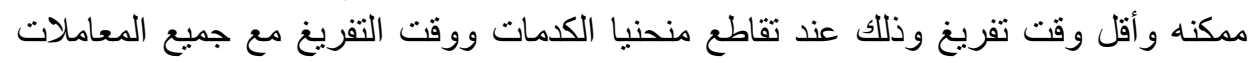

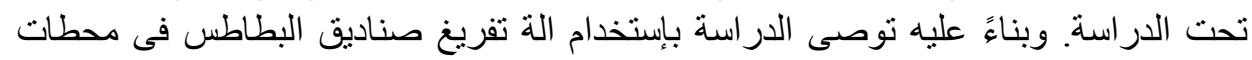

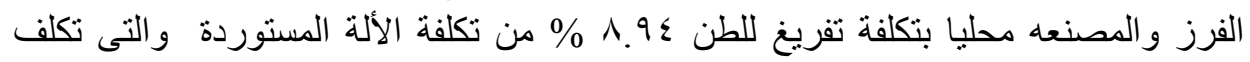

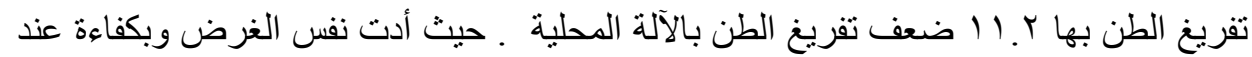
المعاملات الموصى بها.

ثباحث أول ـ معه بحوث الهندسة الزراعية ـ مركز البحوث الزراعية ـ الاقى ـ مصر. 